\title{
Quality of Life for Patients Recovered from Covid-19
}

\author{
F. Benlebna* and F. El Abed \\ Faculty of Medicine, Department of Physical Medicine and Rehabilitation, EHU, Algeria
}

\begin{abstract}
Huge fatigue, breathlessness or attacks of tachycardia; here are some of the symptoms that these COVID-19 patients experience, a few months after being infected with the virus.

This article assesses the quality of life after recovery of patients from COVID-19 infection.

A descriptive study using an anonymous self-questionnaire destined for patients who have been infected and cured of COVID-19. We used two scales: The VQ11 which assesses the quality of life, and the PICHOT measure fatigue.

86 patients were included (70.9\% women and $29.1 \%$ men), mean age 37.69. COVID-19 infection begins an average of 12.2 weeks after clinical recovery. According to the VQ11, the quality of life was impacted in $55.8 \%$ of cases, observed especially in the areas of physical (47.7\%), emotional (50\%), and social life (34.8\%). According to the PICHOT scale, 53.5\% have pathological fatigue; among them $41.8 \%$ report the presence of excessive fatigue.

More studies needed to assess the long-term impact of COVID-19 on patients. As; currently, it is difficult to talk about the extent of the alteration in their quality of life, so it will be necessary to follow these recovered patients in the long term to get a real answer.
\end{abstract}

\section{Keywords}

COVID-19, Quality of life, Sequelae, Fatigue, Self-questionnaire

\section{Introduction}

Currently, the world is going through a serious health crisis with the COVID-19 pandemic. This is a real public health problem because of its mortality, morbidity and impact.

After recovery, patients complain of general illness, muscle pain, arthralgia, fatigue at the slightest physical or intellectual effort, and loss of memory and sometimes fits of tachycardia disrupting activities of daily living [1]. The objective of our study is to appreciate the quality of life of patients recovered from COVID-19 infection.

\section{Materials and Methods}

A prospective, descriptive study was conducted to determine the quality of life for patients recovered from covid-19. We used an anonymous self-questionnaire.

Inclusion criteria

- Patients aged 18 and over ( $\geq 18$ years).

- Patients who presented symptoms related to COVID-19 infection (confirmed by a positive RT-PCR and/or CT test).

- Patients cured for more than 6 weeks ( $\geq 6$ weeks).

Exclusion criteria

- Illiterate patients.
- Patients with other pathologies affecting their quality of life (pathologies chronic respiratory diseases, heart disease, neoplasm's, etc.).

The quality of life was assessed by the VQ11 selfquestionnaire, which was developed by NINOT (2010) and coll. It was formed from around twenty health practitioners (pulmonologists, physiotherapists, nurses, psychologists) and more than 160 COPD patients.

It is made up of 3 areas: Functional, Psychological and Relational [2].

These 3 areas group together eleven (11) questions with five (5) levels of intensity. (Value from 1 to 5: not at all, a little, moderately, a lot and a lot). The total score is 55 . It is fast, reproducible, easy to use and interpret in the optics of being used in routine consultation practice.

*Corresponding author: FF. Benlebna, Faculty of Medicine, Department of Physical Medicine and Rehabilitation, EHU, Oran, Algeria

Accepted: June 12, 2021

Published online: June 14, 2021

Citation: Benlebna F, Abed FE (2021) Quality of Life for Patients Recovered from Covid-19. Res Rev Infect Dis 4(1):145-148 
As well as a PICHOT fatigue scale for the overall assessment of fatigue:

Among the eight (08) propositions, the patient must determine for each item a score between 0 and 4 which best corresponds to his condition

$(0=$ Not at all; 1 = A little; 2 = Moderately; 3 = A lot; 4 = Extremely).

A score greater than or equal to 20 is considered pathological and a total greater than 22 is favor of excessive fatigue [3].

Data entry and analysis are performed with EPI Data version 3.1 and Excel 2007.

\section{Results}

Ninety (90) people answered the questionnaire, 4 were excluded (3 Patients not having a confirmed diagnosis of COVID-19 infection, 1 patient with a cardiovascular history). A total of 86 questionnaires were selected.

61 women and 25 men, average age is 37.69 years [Min = 18 years, $\operatorname{Max}=83$ years]; having presented a infection with COVID-19, the diagnosis was made either by the molecular RT-PCR test ( $88.4 \%)$, and/or by the lung scanner (50\%) (Table 1 and Table 2).

Infection began an average of 12.2 weeks after their "clinical recovery". 38.4\% of people were hospitalized and $61.6 \%$ followed their treatments at home. $88.4 \%$ of patients received vitamin supplementation; $87.2 \%$ received antibiotic treatment; while oxygen therapy was prescribed at $22.1 \%$ (Figure 1).

The average total score of VQ11 in our study is 25.24 points, reflecting an alteration in quality of life after infection with COVID-19.

The mean score functional $=7.6$; the mean score psychological $=9.7$; and the mean score relational $=8.5$.

The quality of life was strongly impacted (VQ11 $\geq 22$ ) in $55.8 \%$ of cases, observed in particular in the areas of physical $(47.7 \%)$, emotional (50\%), and social life (34.8\%).

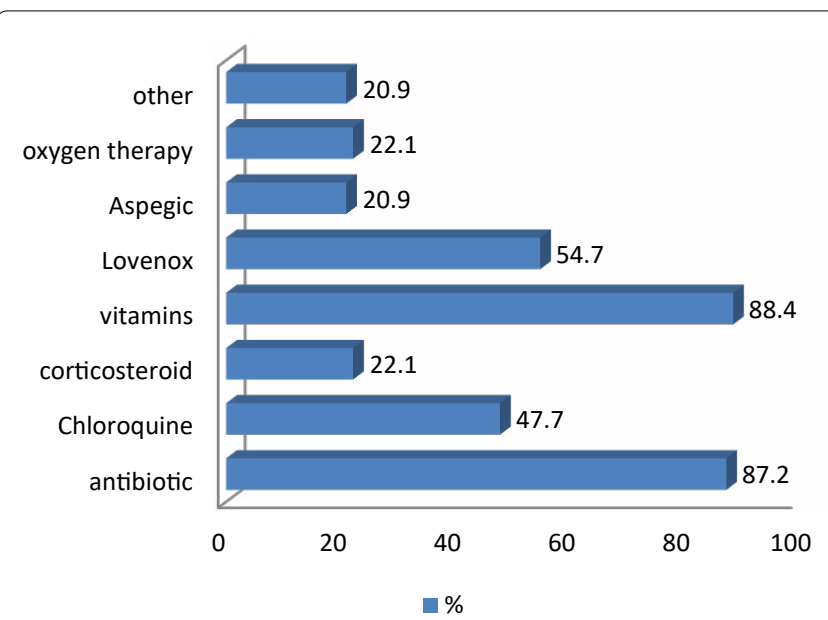

Figure 1: The different treatments used in the acute phase.
Table 1: General characteristics of the population.

\begin{tabular}{|c|c|c|c|}
\hline & $N$ (number) & $\%$ & {$[95 \% \mathrm{Cl}]$} \\
\hline \multicolumn{4}{|l|}{ Sex } \\
\hline oWomen & 61 & 70.9 & {$[60.6-79.5]$} \\
\hline oMen & 25 & 29.1 & {$[20.5-39.4]$} \\
\hline \multicolumn{4}{|l|}{ Profession } \\
\hline o No occupation & 15 & 17.5 & {$[10.2-31.8]$} \\
\hline o Doctor & 20 & 23.3 & {$[15.6-33.2]$} \\
\hline o Nurse & 14 & 16.3 & {$[10-25.5]$} \\
\hline oMidwife & 6 & 7 & {$[3.2-14.4]$} \\
\hline oTeacher & 5 & 5.8 & {$[2.5-12.9]$} \\
\hline oStudent & 4 & 4.7 & [1.8 - 11.4] \\
\hline o Biologist & 2 & 2.3 & {$[0.6-8.1]$} \\
\hline oOther & 15 & 18 & \\
\hline \multicolumn{4}{|l|}{ Smoking } \\
\hline oYes & 8 & 9.3 & {$[4.8-17.3]$} \\
\hline oNo & 78 & 90.7 & {$[82.7-95.2]$} \\
\hline \multicolumn{4}{|c|}{ Positive diagnosis } \\
\hline oRT-PCR + & 76 & 88.4 & [79.9 - 93.6] \\
\hline oTDM + & 43 & 50 & [39.7- 60.3] \\
\hline
\end{tabular}

$\%$ of lung damage on CT scan

\begin{tabular}{|l|c|c|c|}
\hline$[3-20]$ & 18.7 & & \\
\hline$[25-50]$ & 16.3 & & \\
\hline$>50$ & 9.4 & & \\
\hline Antecedents & & & \\
\hline oYes & 25 & 29.8 & {$[21.0-40.3]$} \\
\hline o No & 59 & 70.2 & {$[59.8-79.0]$} \\
\hline Diabetes & 8 & 9.3 & {$[4.8-17.3]$} \\
\hline $\begin{array}{l}\text { Arterial } \\
\text { hypertension }\end{array}$ & 13 & 15.1 & {$[9.1-24.2]$} \\
\hline Hypercholesterolemia & 3 & 3.5 & {$[1.2-9.8]$} \\
\hline Asthma & 3 & 3.5 & {$[1.2-9.8]$} \\
\hline Other & 8 & 9.6 & \\
\hline
\end{tabular}

Table 2: Describes the main symptoms presented by patients during the acute phase.

\begin{tabular}{|l|c|c|c|}
\hline & $\mathbf{N}$ (number) & $\mathbf{\%}$ & {$[\mathbf{9 5 \% ~ C l ] ~}$} \\
\hline Fever & 63 & 73.3 & {$[63.1-81.5]$} \\
\hline Headache & 70 & 81.4 & {$[71.9-88.2]$} \\
\hline Cough & 55 & 64 & {$[53.4-73.3]$} \\
\hline Anosmia & 59 & 68.6 & {$[58.2-77.4]$} \\
\hline Agueusia & 51 & 59.3 & {$[48.7-69.1]$} \\
\hline Nasal obstruction & 28 & 32.6 & {$[23.6-43]$} \\
\hline Diarrhea & 55 & 64 & {$[53.4-73.3]$} \\
\hline Dyspnea & 45 & 52.3 & {$[41.9-62.6]$} \\
\hline $\begin{array}{l}\text { Other (asthenia, } \\
\text { stiffness...) }\end{array}$ & 32 & 38.4 & \\
\hline
\end{tabular}

As well $45.3 \%$ reported the presence of fatigue (Much to extremely) in their activities of daily living, $20.9 \%$ suffered physical sequelae (Many), and $24.4 \%$ of psychic sequelae (Many) (Figure 2).

The PICHOT scale showed that $53.5 \%$ of patients have pathological fatigue (score $\geq 20$ ). Among them, $41.8 \%$ reported the presence of excessive fatigue (score $>22$ ). Pathological or abnormal fatigue is fatigue that occurs more quickly and persists chronically, the person feels disabled compared to his usual level of fitness to carry out his daily activities. 


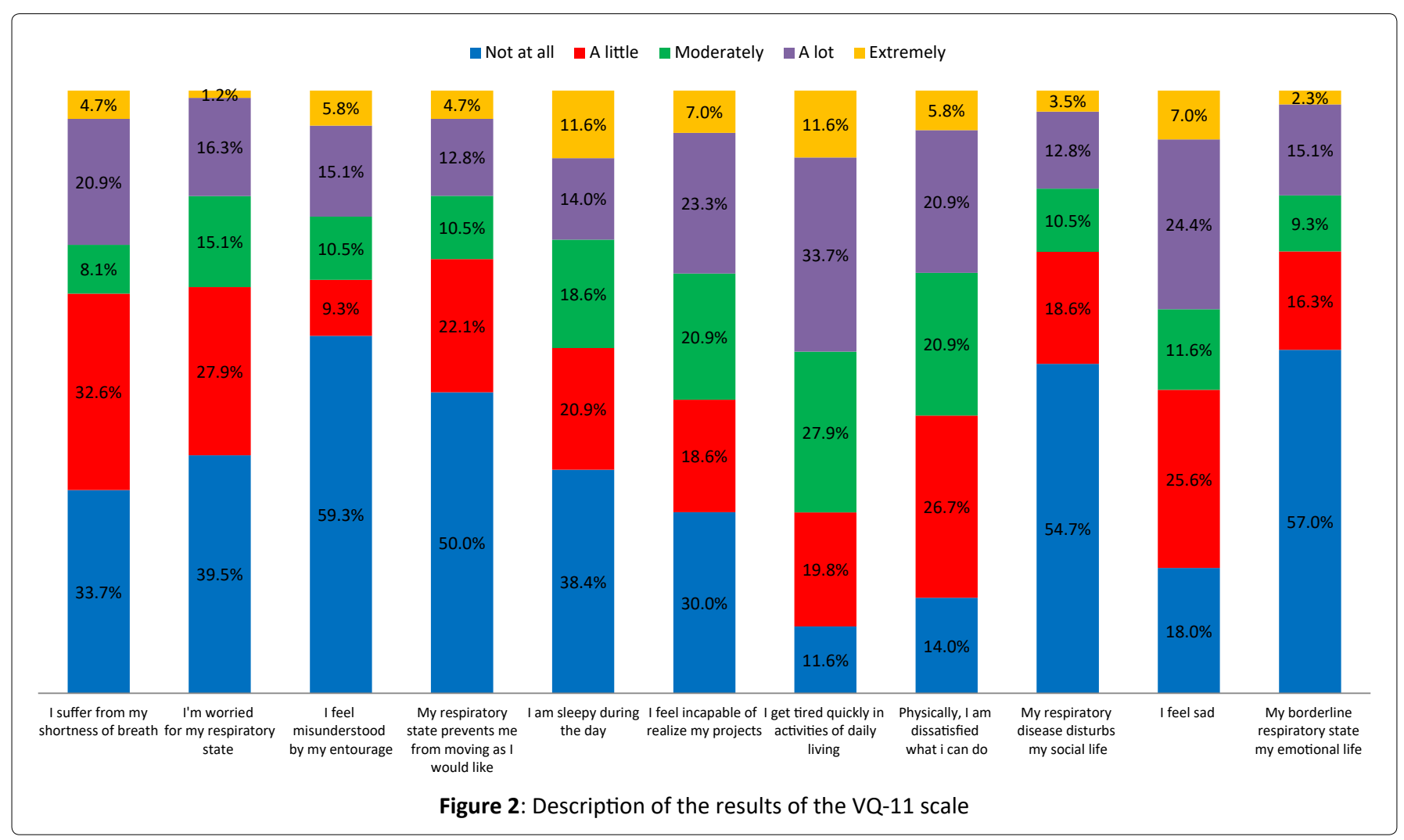

Table 3: Description of the results of the PICHOT fatigue scale.

\begin{tabular}{|c|c|c|c|c|c|c|c|c|c|c|}
\hline & \multicolumn{2}{|c|}{$0=$ not at all } & \multicolumn{2}{|c|}{ 1= a little } & \multicolumn{2}{|c|}{$2=$ moderately } & \multicolumn{2}{|c|}{$3=a$ lot } & \multicolumn{2}{|c|}{$4=$ extremely } \\
\hline & $\%$ & {$[95 \% \mathrm{Cl}]$} & $\%$ & [95\% Cl] & $\%$ & {$[95 \% \mathrm{Cl}]$} & $\%$ & {$[95 \% \mathrm{Cl}]$} & $\%$ & {$[95 \% \mathrm{Cl}]$} \\
\hline I lack energy & 8.1 & {$[4.0-15.9]$} & 15.1 & [9.1 - 24.2] & 23.3 & [15.6 - 33.2] & 29.1 & [20.5 - 39.4] & 24.4 & [16.6 - 34.5] \\
\hline $\begin{array}{l}\text { Everything takes } \\
\text { effort }\end{array}$ & 9.3 & {$[4.8-17.3]$} & 23.3 & [15.6 - 33.2] & 22.1 & [14.6 - 31.9] & 30.2 & [21.5 - 40.6] & 15.1 & [9.1 - 24.2] \\
\hline $\begin{array}{l}\text { I feel weak in some } \\
\text { parts of the body }\end{array}$ & 15.1 & [9.1 - 24.2] & 5.8 & {$[2.5-12.9]$} & 29.1 & [20.5 - 39.4] & 26.7 & [18.5 - 36.9] & 23.3 & [15.6 - 33.2] \\
\hline $\begin{array}{l}\text { I have heavy arms } \\
\text { or legs }\end{array}$ & 22.1 & [14.6 - 31.9] & 14.0 & [8.2 - 22.8] & 8.1 & {$[4.0-15.9]$} & 32.6 & [23.6 - 43.0] & 23.3 & [15.6 - 33.2] \\
\hline $\begin{array}{l}\text { I feel tired for no } \\
\text { reason }\end{array}$ & 9.3 & {$[4.8$ - 17.3] } & 19.8 & [12.7 - 29.4] & 16.3 & [10.0 - 25.5] & 29.1 & [20.5 - 39.4] & 25.6 & [17.5 - 35.7] \\
\hline $\begin{array}{l}\text { I want to lie down } \\
\text { to rest }\end{array}$ & 8.1 & {$[4.0-15.9]$} & 20.9 & [13.7 - 3.07] & 18.6 & [11.8 - 28.1] & 20.9 & [13.7 - 30.7] & 31.4 & [22.6 - 41.8] \\
\hline $\begin{array}{l}\text { I have trouble } \\
\text { concentrating }\end{array}$ & 26.7 & [18.5 - 36.9] & 12.8 & [7.3 - 21.5] & 8.1 & [4.0 - 15.9] & 30.2 & [21.5 - 40.6] & 22.1 & [14.6 - 31.9] \\
\hline $\begin{array}{l}\text { I feel tired, heavy } \\
\text { and stiff }\end{array}$ & 14.0 & {$[8.2-22.8]$} & 15.1 & [9.1 - 24.2] & 12.8 & [7.3 - 21.5] & 34.9 & [25.7 - 45.4] & 23.3 & [15.6 - 33.2] \\
\hline
\end{tabular}

Of the 86 study participants, $29.1 \%$ reported persistent fatigue scored at 3 , with concentration problems scored at 3 reported in $30.2 \%$ of cases (Table 3 ).

\section{Discussion}

At this point in the COVID-19 pandemic, very few studies have been done to assess the quality of life after recovery [4]. But many studies have been carried out around the sequelae of two other infections respiratory infections, SARS and MERS.

In the literature, long-term sequelae are defined as: "Any symptom that appears after 6 weeks or that persists for more than 6 weeks after the onset of symptoms of COVID19, except for symptoms and complications attributable to the acute phase of the infection" [4].
In our study, the infection began an average of 12.2 weeks after they had healed we consider that $55.8 \%$ have an alteration in their quality of life, and $53.5 \%$ keep pathological fatigue and physical deconditioning.

More than half of patients and staff at an Irish hospital have suffered from fatigue persistent after recovering from COVID-19, regardless of the severity of their infection; according to one studied on average ten weeks after clinical recovery of 128 patients (age average: 50 years), this study also showed that $52 \%$ reported fatigue persistent, regardless of the severity of their initial infection [5].

Psychic sequelae are also common after SARS, even after several months: Post-traumatic stress disorder in 
(39\%) of patients, depression (33\%) or anxiety (30\%). The measurement of the quality of life by the SF-36 questionnaire showed lasting sequelae on social life, even after a year. Fatigue and pain were present in about one third of people with SARS, lasting up to 40 months. In our study the patients kept functional (47.7\%), emotional (50\%), resounding on their social life activities (34.8\%).

The post COVID-19 functional impact is probably secondary to affected specific to viral infection and alteration of the immune system, but also to "nonspecific" complications of acute respiratory distress syndrome (ARDS), which can progress to restrictive respiratory failure, as well as those of immobility and extended stays in intensive care $[6,7]$.

\section{Conclusion}

Our study highlights the value of assessing the quality of life of patients after their healing, in which it is very often impaired.

Studies are needed to assess the long-term impact of COVID-19 on patients, because it is difficult to talk about the extent of the deterioration in their quality of life, it will therefore be necessary follow these long-term cured patients to get a real response

\section{References}

1. (2020) The aftermath of COVID-19 Opinion of the National Academy of Medicine.

2. M Dewolf (2017) EPIC study: Evaluation by self-questionnaire of quality of life, VQ11, the impact of bronchodilator treatment in Chronic Obstructive Pulmonary Disease in pulmonary practice. CHU Amiens Picardie.

3. J Gardenas, et al. (2002) PICHOT fatigue scale "Scales and tools evaluation in general medicine". The Generalist- Supplement to $N^{\circ} 2187$.

4. (2020) COVID-19 and the long-term sequelae - What we so far know about. Public Health Ontario, Toronto.

5. (2020) After Covid-19 and the symptom of persistent fatigue. Huff Post News.

6. HAS (2020) Management of COVID + patients in Physical Medicine and Rehabilitation (MPR), and return home. Rapid responses in the context of COVID-19.

7. J Yves Nau (2020) COVID-19: What do we know today about its different after-effects? Swiss Medical Review, 1466.

DOI: $10.36959 / 719 / 581$

Copyright: (c) 2021 Benlebna F. This is an open-access article distributed under the terms of the Creative Commons Attribution License, which permits unrestricted use, distribution, and reproduction in any medium, provided the original author and source are credited. 